\title{
Solving The Environmental Economic Dispatch Problem using Whale Optimization Algorithm Haider J.Touma,
}

Master Degree in Electrical Power Engineering from University of Technology, Iraq.

Email : haidertomah@yahoo.com

\begin{abstract}
:
In this work, the Whale Optimization Algorithm method used to solve the Environmental Economic Dispatch Problem. The performance of the used algorithm is substantiated using standard test system of three thermal generating units. The proposed algorithm produced optimum or near optimum solutions. The obtained results in this study using the Whale Optimization Algorithm are compared with the obtained results using other intelligent methods such as Particle Swarm Optimization, Simple Genetic Algorithm and Genetic Algorithm. The comparison demonstrated the obtained results in this research are close to these obtained using the above revealed approaches.
\end{abstract}

Key words:

Particle Swarm Optimization (PSO), Simple Genetic Algorithm (SGA), Genetic Algorithm(GA), Whale Optimization Algorithm (WOA), Environmental Economic Dispatch (EED).

\section{Introduction}

The economic dispatch represents important concern in the controlling of power system operation. The main target for economic dispatch is how to schedule the generating units to ensure minimum generation cost for the electricity utilities to achieve highest profits and to be more competitive in the electricity market $[1,2,3,4]$. This aim has faced the environmental challenges. Because the electric power generation often depends on thermal units which are operating with fossil fuel (oil, coal, natural gas). Using such fuels leads to emission of dangerous diverse gases such as carbon dioxides and sulfur dioxide. The emission of mentioned gases has represented main cause of the global warming problem and thus main cause in different environmental problems such as temperature increase, rain acid as well as healthy problems such as cancer diseases. The Environmental Economic Dispatch (EED) signifies one of the important necessities of the power system operation as a measure to deal with the emission problem. The chief role of (EED) is attaining minimum cost and minimum emission. Since the minimum cost implies the emissions will be secondary, then again, minimum emission implies increasingly extra cost and taxes for emissions treatment in this manner, the two destinations are clashing $[5,6,7,8]$. This study attempts to solve EED by using one of latest meta heuristic algorithms which has sufficient aspects such as precision and fast convergence.

II. Mathematical Formulation [ 3, 9, 14]

\subsection{Electrical Constraints}

The fuel-cost function in the most studies is a second order equation as described in equation (1).

$\mathrm{FC}_{\mathrm{i}}=\mathrm{a}_{\mathrm{i}} \mathrm{P}_{\mathrm{i}}^{2}+\mathrm{b}_{\mathrm{i}} \mathrm{P}_{\mathrm{i}}+\mathrm{c}_{\mathrm{i}} \quad(\$ / \mathrm{h})$ 
The generator limits describe the electrical inequality constraints in the economic dispatch formulation $[10,11]$.

$\mathrm{P}_{\mathrm{i} \min } \leq \mathrm{P}_{\mathrm{i}} \leq \mathrm{P}_{\mathrm{imax}} \quad \mathrm{i}=1, \ldots, \mathrm{n}$

For proper reliable operating conditions, the total generation is more than the total load demand and transmission losses. Transmission losses has two significant impacts on the optimal economic scheduling of the generators .First, the total real power loss in the system increases the total generation demand, and second the generation schedule may have to be adjusted by shifting generation to diminish flows on transmission circuits because they would otherwise become overloaded [1].

the losses of power system $[12,13]$ can be represented in the form given by equation (2).

$$
\mathrm{P}_{\mathrm{L}}=\sum_{i=1}^{n} \sum_{\mathrm{j}=1}^{\mathrm{n}} \mathrm{P}_{\mathrm{i}} \mathrm{B}_{i j} \mathrm{P}_{\mathrm{j}}+\sum_{\mathrm{j}=1}^{\mathrm{n}} \mathrm{B}_{0 \mathrm{j}} \mathrm{P}_{\mathrm{j}}+\mathrm{B}_{00}
$$

The coefficients $B_{i j}$ are called loss coefficients or B - coefficients. The impact of losses on the scheduling of the generators has been described by equation (3) which represents the electrical equality constraints in the problem .

$\mathrm{P}_{\mathrm{D}}=\sum_{i=1}^{n} \mathrm{P}_{i}-\mathrm{P}_{\mathrm{L}}$

\subsection{Environmental Constraints}

The environmental constraint makes utilities and consumers partners in facing this challenge, thus as it was explained, the regulated taxes on the pollutants emissions represent a part of solution for the environmental problem to reduce or control the emission quantities. Practically, the emission function of each thermal generating unit is characterized as quadratic smooth function similar to the fuel cost function with measuring unit kilogram of a certain emission per hour $(\mathrm{Kg} / \mathrm{h})$ as shown below.

$$
E C_{i}=d_{i} P_{i}^{2}+e_{i} P_{i}+f_{i}
$$

In order to transform the emission function $(\mathrm{kg} / \mathrm{h})$ to emission cost function needing to multiplying the emission function by control or penalty factor(hi) measured by $(\$ / \mathrm{kg})$ which is obtained by dividing the maximum fuel cost of generating unit $\left(\mathrm{FC}_{\mathrm{imax}}\right)$ by maximum emission of it $\left(\mathrm{EC}_{\mathrm{imax}}\right)$ ,thus the produced function measured by $(\$ / \mathrm{h})$ such as fuel cost function then by adding the produced function(emission cost function ) to the fuel cost function getting the total cost function $[6,14,11]$.

The mathematical formulation of EED can be explained as below:

The price penalty factor of each generating unit (hi) is obtained as follows:

$\mathrm{h}_{\mathrm{i}}=\frac{\mathrm{EC} \text { imax }}{\text { FC imax }}$

Where,

$E_{\text {imax }}=d_{i} P_{i \max }{ }^{2}+e_{i} P_{i \max }+f_{i}$
$F_{i \max }=a_{i} P_{i \max }{ }^{2}+b_{i} P_{i \max }+c_{i}$ 
The minimization problem for the EED will be :

$\operatorname{minimize} \mathrm{f}(\mathrm{FC}, \mathrm{EC})=\min \left(\mathrm{FC}+\sum \mathrm{h}_{\mathrm{i}} \mathrm{EC}_{\mathrm{i}}\right)$

III. The proposed algorithm Whale Optimization Algorithm (WOA) [ 15, 16, 17]:

\subsection{Introduction}

The Whale Optimization Algorithm (WOA) has been built on the whale hunting technique. This is pursuing procedure is called bubble-net feeding strategy. Humpback whales want to chase little fishes near the surface by making bubble net around the prey rises along a circle path as shown in figure 1.

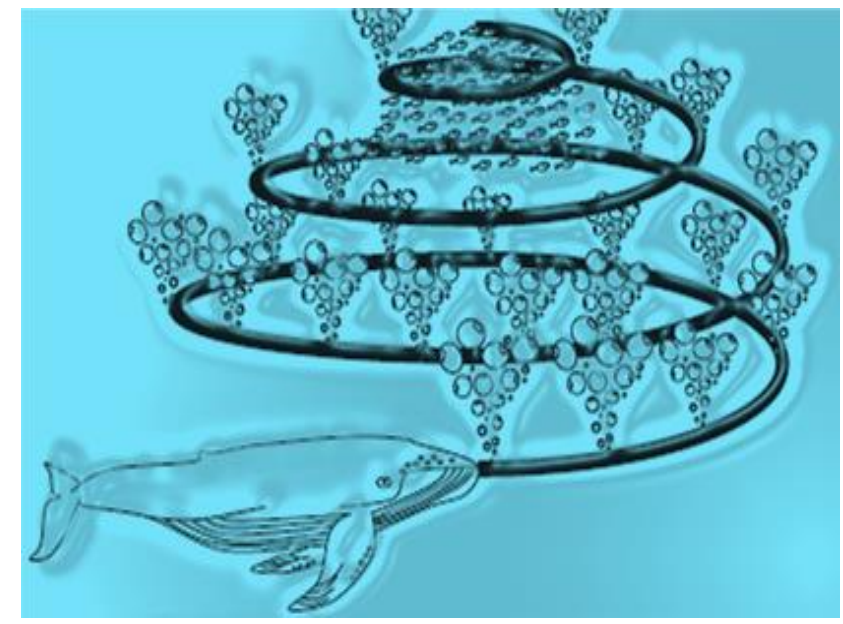

Figure 1 . Bubble-net feeding technique of humpback whales

\subsection{Mathematical Formulation [17]}

$$
\begin{aligned}
& D=\left|C \cdot X^{*}(t)-X(t)\right| \ldots \\
& X(t+1)=X^{*}(t)-A . D
\end{aligned}
$$

Where

$\mathrm{t}$ present iteration,

A and C coefficient vectors,

$\mathrm{X}^{*} \quad$ position vector of the best solution

$\mathrm{X}$ position vector,

II absolute value 


$$
\begin{aligned}
& \mathrm{A}=2 \mathrm{a} \cdot \mathrm{r}-\mathrm{a} \ldots \ldots(9.3) \\
& \mathrm{C}=2 \cdot \mathrm{r} \quad \ldots \ldots \ldots(9.4)
\end{aligned}
$$

where

a is linearly diminished from 2 to 0 through the number of iteration (in both investigation and exploitation stages) and $\mathrm{r}$ is an arbitrary vector in $[0,1]$.

\subsubsection{Bubble-net assaulting strategy (exploitation stage):}

Two approaches are utilized to figure the air bubble net conduct of humpback whales as below:

i. Shrinking circling system:

Eq.(9.3) has explained this approach . The fluctuation scope of A is additionally diminished by a . As such A will be random in the interval [ $-\mathrm{a}$, a ] , where a is diminished from 2 to 0 throughout iterations . A is in $[-1,1]$, the new position of a search operator has been estimated between the first position of the agent and the position of the present best agent. Figure. 2 (a) shows this behavior.

ii. Spiral updating position:

This approach shown in figure 2.(b) depends on determining the distance between the whale situated at $(\mathrm{X}, \mathrm{Y})$ and prey situated at $\left(\mathrm{X}^{*}, \mathrm{Y}^{*}\right)$. Eq (9.5) represents the spiral path between the position of whale and prey .

$\mathrm{X}(\mathrm{t}+1)=\mathrm{D}^{\prime} \cdot \mathrm{e}^{\mathrm{bl}} \cdot \cos (2 \pi \mathrm{l})+\mathrm{X}^{*}(\mathrm{t})$

where $D^{\prime}=\left|X^{*}(t)-X(t)\right|$ and demonstrates the separation of the $i$ th whale to the prey (best solution), $\mathrm{b}$ is a constant for characterizing the state of the logarithmic spiral , 1 is an random number in $[-1,1]$. Whales swim around the prey inside Shrinking circle and along a spiral form . There is a probability of half to select one of two approaches as shown :

$$
\mathrm{X}^{*}(\mathrm{t})-\mathrm{A} . \mathrm{D} \quad \text { if } \mathrm{p}<0.5
$$

$X(t+1)=$

$$
D^{\prime} \cdot e^{b l} \cdot \cos (2 \pi l)+X^{*}(t) \quad \text { if } p \geq 0.5
$$




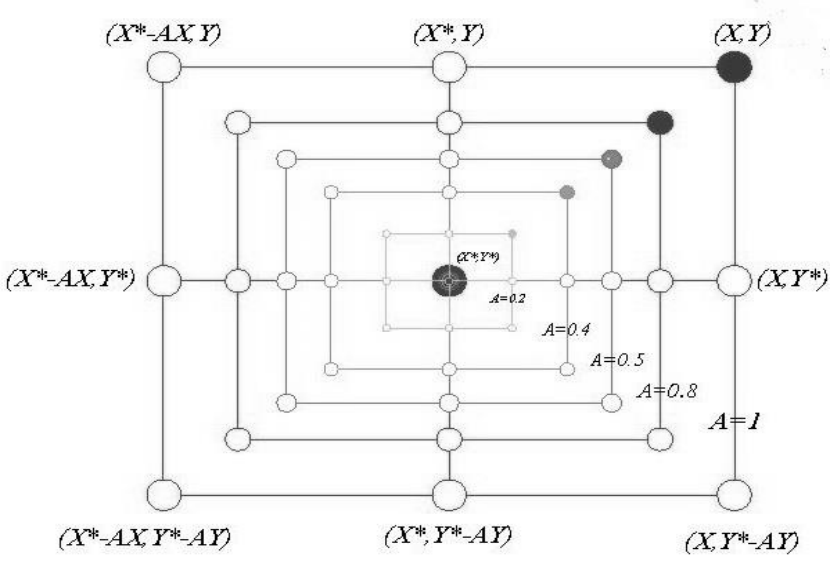

Figure. 2 ( a) shrinking encircling mechanism

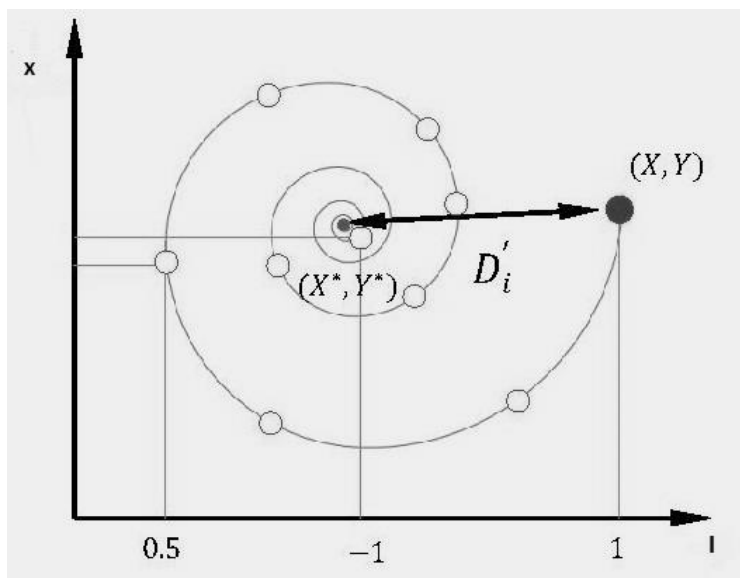

Figure 2 (b) spiral updating position.

where $\mathrm{p}$ is an arbitrary number in $[0,1]$.

\subsubsection{Scan for prey (investigation stage)}

whales pursue randomly as per the position of each other. Thus, A is utilized with the random values more than 1 or under -1 to make search agent to move far from a reference whale. The position of search agent has been updated in the investigation stage as per a randomly picked search agent rather than the best pursuit agent discovered in this way. This scheme and $|\mathrm{A}|>1$ highlight investigation and tolerate the WOA calculation to perform a global pursuit. The mathematical model is as per the following:

$\mathrm{D}=\left|\mathrm{C} \cdot \mathrm{X}_{\text {rand }}-\mathrm{X}\right|$

$\mathrm{X}(\mathrm{t}+1)=\mathrm{X}_{\text {rand }}-\mathrm{A} \cdot \mathrm{D}$

The WOA can be summarized in the below:

Step-1 : $\quad$ Initialize the whales population $\mathrm{X}_{\mathrm{i}}(\mathrm{i}=1,2, \ldots, \mathrm{n})$

Step-2 : Calculate the fitness of each search agent $\mathrm{X}^{*}=$ the best search agent

Step-3: for each search agent

Update a, A, C, l, and $\mathrm{p} \quad$ (while $\mathrm{t}<$ maximum number of iterations)

Step-4 : if $1(\mathrm{p}<0.5)$ if $|\mathrm{A}|<1$

Step-5 : Update the position of the current search agent by the Eq.(9.1)

Step-6 : if2 1 A $1 \geq 1$

Select a random search agent $\left(\mathrm{X}_{\text {rand }}\right)$ 
Update the position of the current search agent by the Eq.(9.9)

Step-7 : if1 $(\mathrm{p} \geq 0.5)$

Update the position of the current search by the Eq. (9.5)

Step-8 : if

Any search agent goes beyond the search space and amend it Calculate the fitness of each search update $X^{*}$

if there is a better solution $t=t+1$

Step-9 : select new $\mathrm{X}^{*}$

\section{CASE STDUIED AND RESULTS}

In this study, the (WOA) method has been executed. The application is performed on standard test system of three thermal generating units. The Matlab 7.8 version is used throughout this work on a laptop of Intel processor , CPU M 350@ 2.27 GHZ,RAM 4 GB(2.99G B usable, operating system 32 bit).

\subsection{Three-Generating Units Test System [7, 8, 18 ]}

The necessary data required for this case are presented in tables 1 and 2. The B-coefficients for the power demands under study are shown in table 3

Table 1 Fuel Cost Function Parameter

\begin{tabular}{|c|c|c|l|c|c|}
\hline $\begin{array}{l}\text { Unit } \\
\text { No. }\end{array}$ & \multicolumn{3}{|c|}{ Fuel Cost Coefficients } & \multicolumn{2}{c|}{ Generation Limits } \\
\hline & $\mathrm{a}\left(\$ / \mathrm{MW}^{2} \mathrm{~h}\right)$ & $\mathrm{b}(\$ / \mathrm{MWh})$ & $\mathrm{c}(\$ / \mathrm{h})$ & $\begin{array}{l}\text { Pmin } \\
(\mathrm{MW})\end{array}$ & $\begin{array}{l}\text { Pmax } \\
(\mathrm{MW})\end{array}$ \\
\hline 1 & 0.03546 & 38.30553 & 1243.531 & 35 & 210 \\
\hline 2 & 0.02111 & 36.32782 & 1658.5696 & 130 & 325 \\
\hline 3 & 0.01799 & 38.27041 & 1356.6592 & 125 & 315 \\
\hline
\end{tabular}

Table 2 Emission Function Parameters

\begin{tabular}{|l|c|c|c|}
\hline $\begin{array}{l}\text { Unit } \\
\text { No. }\end{array}$ & \multicolumn{3}{|c|}{ Emission Function Coefficients } \\
\hline & $\mathrm{d}\left(\mathrm{kg} / \mathrm{MW}^{2} \mathrm{~h}\right)$ & $\mathrm{e}(\mathrm{kg} / \mathrm{MWh})$ & $\mathrm{f}(\mathrm{kg} / \mathrm{h})$ \\
\hline 1 & 0.00683 & -0.54551 & 40.26690 \\
\hline 2 & 0.00461 & -0.51160 & 42.89553 \\
\hline 3 & 0.00461 & -0.51160 & 42.89553 \\
\hline
\end{tabular}




\section{Table 3 B-coefficients}

\begin{tabular}{|c|c|c|}
\hline \multicolumn{3}{|l|}{$\mathrm{B}=$} \\
\hline 0.000071 & 0.000030 & 0.000025 \\
\hline 0.000030 & 0.000069 & 0.000032 \\
\hline 0.000025 & 0.000032 & 0.000080 \\
\hline
\end{tabular}

Tables 4 and 5 illustrate a comparison results have been nominated from literature and those obtained by new strategy involving WOA. The results show emission and total cost. The results of WOA are very competitive and reliable. It's mentionable the obtained results regard losses are competitive too, but the concentration in this study is on the cost and emission.

Table 4 .Total Cost ( \$/h) Results Comparison for The 3-Unit System

\begin{tabular}{|l|l|l|l|l|}
\hline $\begin{array}{l}\text { Load } \\
\text { (MW) }\end{array}$ & WOA & GA[8] & SGA[18] & PSO [8] \\
\hline 400 & 29856 & 29563.2 & 29820 & 29559.9 \\
\hline 500 & 39489 & 39220.1 & 39441 & 39210.2 \\
\hline 700 & 64733 & 64866.2 & 66659 & 64862 \\
\hline
\end{tabular}

Table 5 .Total Emission (kg/h) Results Comparison for The 3-Unit System

\begin{tabular}{|c|l|l|c|c|}
\hline $\begin{array}{l}\text { Load } \\
\text { (MW) }\end{array}$ & WOA & GA[8] & SGA[18] & PSO [8] \\
\hline 400 & 200.4654 & 200.256 & 201.35 & 200.221 \\
\hline 500 & 311.7782 & 311.273 & 311.89 & 311.15 \\
\hline 700 & 652.8810 & 651.631 & 652.04 & 651.569 \\
\hline
\end{tabular}

\section{Conclusion}

(WOA) has been utilized to determine the optimal solution for the EED problems. This algorithm has been tested on system of three thermal generating units. A general conclusion can be indicated here the proposed technique produced optimal or near optimal solutions. The obtained results for the certain test system explain and verify some facts such as the closeness in general between the (WOA) method and the mentioned techniques in the obtained results as it is proved in the case studied. The load variation reveals on the performance of used optimization technique as shown in Figures 3and 4. 


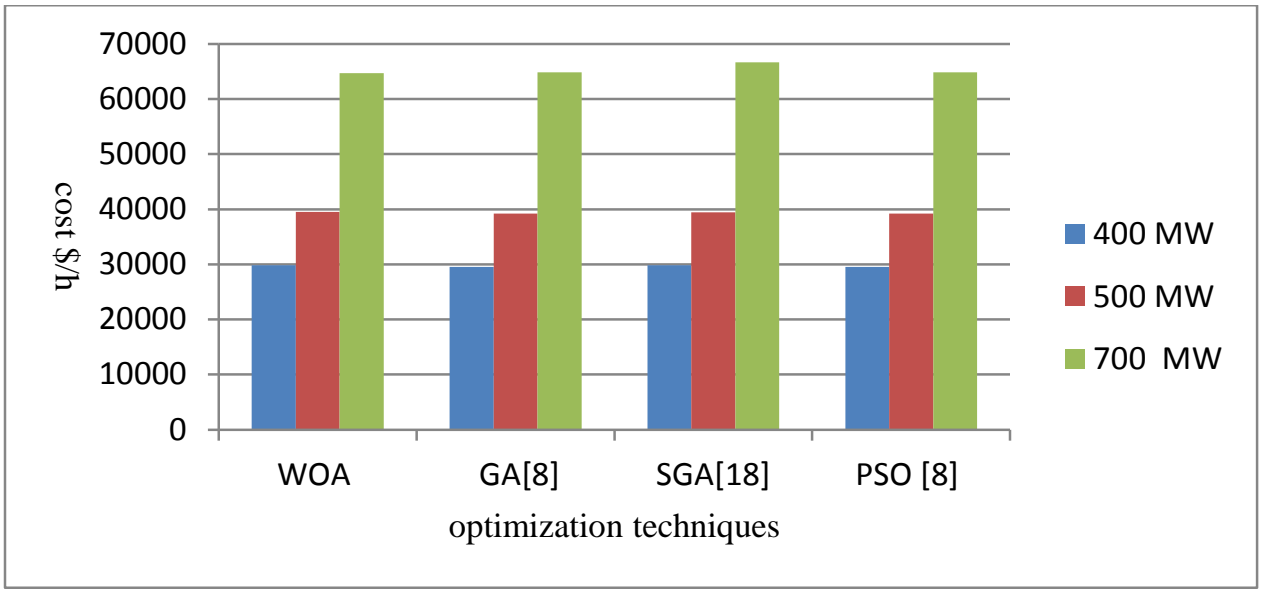

Figure 3. Comparison in total $\operatorname{cost}(\$ / \mathrm{h})$ between the proposed algorithm and these selected from literature

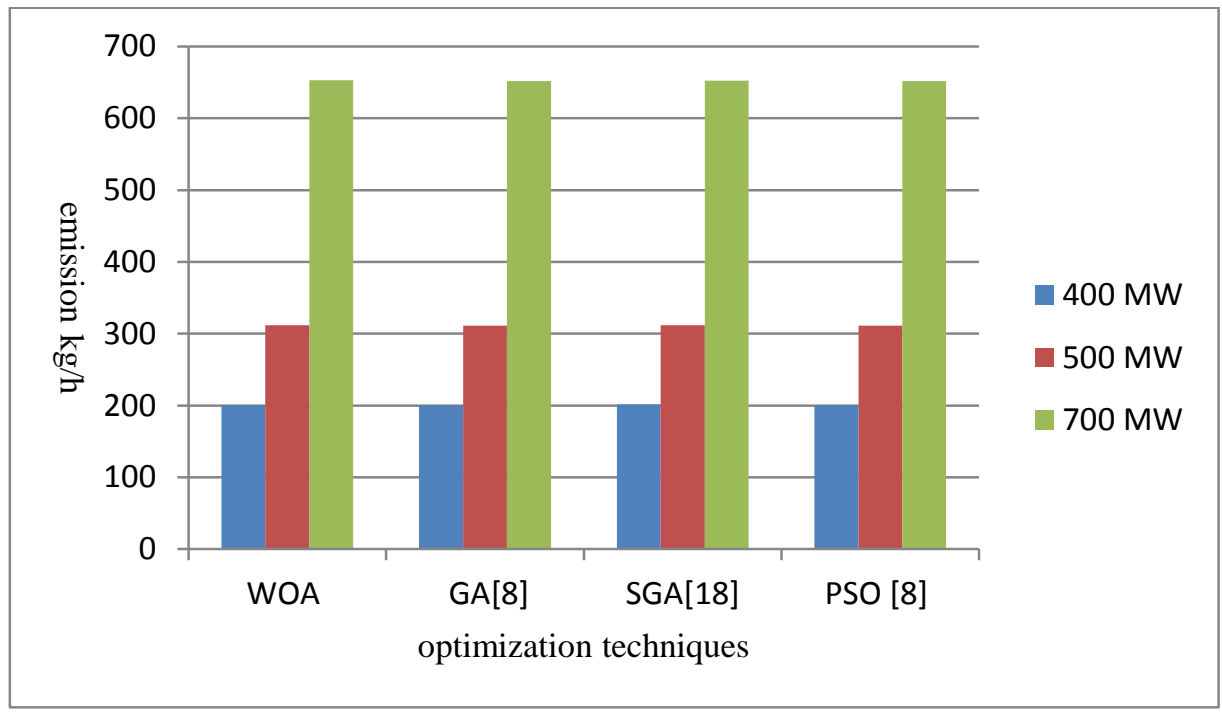

Figure 4. Comparison in total emission $(\mathrm{kg} / \mathrm{h})$ between the proposed algorithm and these selected from literature

Nomenclature

$\mathrm{FC}_{\mathrm{i}} \quad$ fuel cost of unit (i) in $\$ / \mathrm{h}$.

$P_{i} \quad$ real power output of generator $i$.

a $\left(\$ / M^{2} h\right), b(\$ / M W h)$ and c $(\$ / h) \quad$ cost coefficients.

$\mathrm{n}$ number of units

$\mathrm{P}_{\mathrm{i} \text { min }}$ minimum limit for generating unit (i) in MW. 
$\mathrm{P}_{\mathrm{i} \max }$ maximum limit for generating unit (i) in $\mathrm{MW}$.

$\mathrm{P}_{\mathrm{L}} \quad$ total losses in MW.

$\mathrm{P}_{\mathrm{D}} \quad$ total load demand in MW.

FC total fuel cost $(\$ / h)$.

B loss coefficients

$h_{i} \quad$ price penalty factor of the generating unit (i) in $(\$ / \mathrm{kg})$.

$\mathrm{EC}_{\text {imax }}$ maximum limit emission of generating unit (i) in $\mathrm{kg} / \mathrm{h}$

$\mathrm{EC}_{\mathrm{i}}$ : emission of generating unit (i) in $(\mathrm{kg} / \mathrm{h})$.

$\mathrm{d}\left(\mathrm{kg} / \mathrm{MW}^{2} \mathrm{~h}\right), \mathrm{e}(\mathrm{kg} / \mathrm{MWh})$ and $\mathrm{f}(\mathrm{kg} / \mathrm{h}) \quad$ emission coefficients

$\mathrm{FC}_{\text {imax }}$ maximum fuel cost of generating unit (i) in $\$ / \mathrm{h}$

EC total emission in $(\mathrm{kg} / \mathrm{h})$

FC total fuel cost $(\$ / h)$

\section{REFRENCES}

[1] Allen J.Wood \& Bruce F. Wollen berg, "Power Generation , Operation and Control”, John Wily \& Sons ,Inc, USA; 1996.

[2] M.E.El-Hawary \&G.S.Christensen, "Optimal Economic Operation of Electrical Power System ", by Academic Press,Inc ; 1994.

[3] P.Ajay-D-Vimal Raj, et.al, "Optimal Power Flow Solution for Combined Economic Emission Dispatch Problem using Particle Swarm Optimization Technique", Journal of Electrical System JES ; (2007).

[4] Tarek Bouktir, et.al "Economic Power Dispatch Of Power System With Pollution Control Using Multiobjective Particle Swarm Optimization”, University of Sharjah ,Journal of Pure \& Applied Sciences Volume 4, No. 2 ; 2007

[5] M. R. Alrashidi, et.al "Impact of Loading Conditions on The Emission- Economic Dispatch ", World Academy of Science, Engineering and Technology; 2008 .

[6] Sasikala. J \& Ramaswamy. M " "Optimal $\lambda$ based Economic Emission Dispatch using Simulated Annealing", International Journal of Computer Applications (0975 - 8887) Volume 1 -No. 10; 2010.

[7] K. Senthil \& K. Manikandan ,“ Improved Tabu Search Algorithm to Economic Emission Dispatch with Transmission Line Constraint ", International Journal of Computer Science Communication Vol. 1, No. 2; July-December 2010, pp. 145-149, 2010 .

[8] A.Lakshmi Devi and O. Vamsi Krishna "“Combined Economic And Emission Dispatch Using Evolutionary Algorithms-A Case Study”, Asian Research Publishing Network (ARPN), VOL. 3, NO. 6; DECEMBER, 2008 .

[ 9] RMS Danaraj, et.al , "Quadratic Programming Solution to Emission and Economic Dispatch Problem”, IE(I) Journal -EL Vol,86;September 2005.

[10] Kyung-Il Min, Su-Won Lee, et.al ,“An Economic Dispatch Algorithm as Combinatorial Optimization Problems”, International Journal of Control, Automation, and Systems, vol. 6 , no. 4, pp. 468-476; August 2008 . 
[11] Jong-Bae Park, et.al , “An Improved Particle Swarm Optimization for Economic Dispatch with Valve-Point Effect”, International Journal of Innovations in Energy Systems and Power, Vol. 1, no. 1; (November 2006).

[12] John J. Grainger, et.al, "Power System Analysis", by Mc Grew Hill. Inc ； 1994

[13] Hadi Saadat "Power System Analysis ", by Mc Grew Hill. Inc; 1999

[14] R Gnanadass, Narayana Prasad Padhy, et.al , "A New method for the Transmission Congestion Management in the Restructured Power Market ", Faculty of Electrical Engineering Universiti Teknologi Malaysia , ELEKTRIKA ,VOL. 9, NO. 1, PP.52-58; 2007.

[15] Watkins WA, Schevill WE . "Aerial observation of feeding behavior in four baleen whales: Eubalaena glacialis , Balaenoptera borealis , Megaptera novaean- gliae , and Balaenoptera physalus". J Mammal 1979:155-63

[16] Goldbogen JA, Friedlaender AS , Calambokidis J , Mckenna MF , Simon M , Nowacek DP, "Integrative approaches to the study of baleen whale diving be havior, feeding performance, and foraging ecology"; BioScience 2013;63:90-100 ..

[17] Seyedali Mirjalili, Andrew Lewis,“ The Whale Optimization Algorithm”, School of Information and Communication Technology, Griffith University, Nathan Campus, Brisbane,

, QLD 4111, Australia b Griffith College, Mt Gravatt, Brisbane, QLD 4122, Australia, (C2016 Elsevier Ltd. All rights reserved.

[18 ] M Sudhakaran,et.al "Application of Refined Genetic Algorithm to Combined Economic and Emission Dispatch”, IE (I) Journal.EL Vol 85;September 2004. 